(capsules, staff, and management time) was less than $\$ 0.20$ per dose. Based on our calculation of deaths averted, this indicates a total marginal cost of less than $\$ 11$ per death averted, making vitamin A supplementation a highly cost effective strategy for increasing child survival which should be sustainable over an extended period. Of course our estimate of cost per death averted is particularly low because of the extremely high underlying mortality and vitamin A deficiency among our population and because of the existence of a viable delivery system on which to add vitamin A distribution; these factors will vary in other settings.

The field work was carried out under the USAID/Nepal integrated rural health and family planning services project with help from Unicef, Nepal. Analysis was supported through the resources for child health project (REACH; John Snow) under a contract with the Agency for International Development, Bureau of Science and Technology, and Office of Health, with additional support for the Asia/Near East Bureau. We wish to thank the field staff in Jumla, notably $\mathrm{Mr}$ D S Adhikari, Mr J R Acharya, Mr L S Buda, and Ms N McGaughey, and the Karnali Technical School. We thank Dr K P West and Dr J E Rohde for advice, Ms L Mott for statistical analysis, Ms J Harjes for help with programming and Dr E R. Greenberg for editorial help.

1 Sommer A, Tarwotjo I, Djunaedi E, West KP, Loeden AA, Tilden R, et al. Impact of vitamin A supplementation on childhood mortality. Lancet 1986;1:1169-73.

2 Muhilal PD, Idjradinata YR, Muherdiyantiningsih, Karyadi D. Vitamin A fortified monosodium glutamate and health, growth, and survival of fortified monosodium glutamate and health, growth, and

3 Rahmathullah L, Underwood BA, Thulasiraj RD, Milton RC, Ramaswamy $\mathrm{K}$, Rahmathullah R, Babu G. Reduced mortality among children is southern India receiving a small weekly dose of vitamin A. N Engl $\mathcal{f} \mathrm{Med}$ 1990;323:929-35.

4 West KP, Pokhrel RP, Katz J, LeClerq SC, Khatry SK, Shrestha SR, et al.
Efficacy of vitamin A in reducing preschool child mortality in Nepal. Lancet 1991;338:67-71.

Vijayaraghavan K, Radhaiah G, Prakasam BS, Sarma KVR, Reddy V. Effect of massive dose vitamin A on morbidity and mortality in Indian children. Lancet 1990;336:1342-5.

6 World Health Organisation Unicef/International Vitamin A Consultative Group Task Force. Vitamin A supplements. A guide to their use in the treatment and prevention of vitamin A deficiency and xerophthalmia. Geneva: WHO, 1988.

7 Pandey MR, Daulaire NMP, Starbuck ES, Houston RM, McPherson $K$ Reduction in total under five mortality in western Nepal through com munity-based antimicrobial treatment of pneumonia. Lancet 1991;338:

8 Brilliant LB, Pokhrel RP, Graset NC, Lepkowski JM, Kolstad A, Hawks W, t al. Epidemiology of Blindness in Nepal. Bull World Health Organ 1985;63:375-86.

9 Zerfas AJ. The insertion tape: a new circumference tape for use in nutritiona assessment. Am f Clin Nutr 1975;28:782-7.

10 Acharia JR, Starbuck ES, Houston RM, Daulaire NMP, Pokhrel RP, Buda LS. Vitamin A deficiency $\mathbf{n}$ a moutain area of Nepal: the 1989 Jumla xerophthalmia survey. In: Proceedings of the twelfth IVACG meeting Kathmandu, Nepal. Washington, DC: International Life Sciences Institutel Nutrition Foundation, 1990

11 Breslow NE, Day NE. Statistical methods in cancer research. Vol 2. The design and analysis of cohort studies. Lyons: International IARC Agency fo Research into Cancer, 1987:49-51, 83-88, 362. (IARC publication No 82.)

12 Coleman MP, Hermon C, Douglas A. Person-years (PYRS): a Fortran progra for cohort study analysis. Version 1.3. Lyons: International Agency fo Research into Cancer, 1989. (IARC internal report No 89/006.)

3 Donner A, Donald A. The analysis of data arising from a stratified design with the cluster as the unit of randomization. Stat Med 1987;6:43-52.

4 McCullagh P, Nelder JS. Generalized linear models. 2nd ed. New York: Chapman and Hall, 1989:198-208.

15 Sommer A, Katz J, Tarwotjo I. Increased risk of respiratory disease and diarrhea in children with preexisting mild vitamin A deficiency. $\mathrm{Am} \mathfrak{f} \mathrm{Clin}$ Nutr 1984;40:1090-5.

16 West KP, Howard GR, Sommer A. Vitamin A and infection: public health implications. Annu Rev Nutr 1989;9:63-86.

17 Feachem RG. Vitamin A deficiency and diarrhoea: a review of interrelationships and their implications for the control of xerophthalmia and diarrhoea. Tropical Disease Bulletin 1987;84:3.

18 Hussey $G D$, Klein $M$. A randomized controlled trial of vitamin A in children with severe measles. N Engl f Med 1990;323:160-4.

19 Lopez de Romana G, Brown KH, Black RE, Kanashiro HC. Longitudinal studies of infectious diseases and physical growth on infants in Huascar, an underprivileged peri-urban community in Lima, Peru. Am $\mathcal{f}$ Epidemiol 989;129:769-84.

(Accepted 13 November 1991 )

\title{
Stability of essential drugs during shipment to the tropics
}

\author{
H V Hogerzeil, A Battersby, V Srdanovic, N E Stjernstrom
}

\section{World Health \\ Organisation, Action Programme on Essential \\ Drugs, 1211 Geneva-27, Switzerland \\ $\mathrm{H}$ V Hogerzeil, MD, technical officer \\ A Battersby, AADIPL, logistics consultant}

Unicef Supply Division,

Freeport, Copenhagen, 2100 Denmark

V Srdanovic, MSC, chief of purchasing, health, and nutrition

Chemical Laboratories, Medical Products Agency, Husargatan 8,751 25

Uppsala, Sweden

NE Stjernstrom, PHD, head

Correspondence to: Dr Hogerzeil.
Abstract

Objective-To determine whether present methods of international transport of essential drugs by sea adversely affect their quality.

Design-Controlled longitudinal study of drug shipments sent by sea from Unicef in Copenhagen to Lagos; to Mombasa and by land to Kampala; and to Bangkok. 11 essential drugs were stored in four locations on board the ships.

Setting-Main shipping routes from Unicef, Copenhagen, to tropical countries.

Main outcome measures-Temperature and relative humidity in the test packs during the journey. Amount of active ingredient in the drugs before and after shipment.

Results-Temperatures recorded within the test packs range from $-3 \cdot 5^{\circ} \mathrm{C}$ to $42.4^{\circ} \mathrm{C}$ and were $3-12^{\circ} \mathrm{C}$ higher than the ambient temperature. Relative humidity within the packs ranged from $20 \%$ to $88 \%$. Differences between the locations on board were negligible. Ergometrine injection, methylergometrine injection, and retinol capsules lost $1 \cdot 5-5 \cdot 8 \%$ of their activity. Ampoules of ergometrine showed a large variation in the amount of active ingredient after shipment, with three of 80 samples having concentrations $60 \%$ below those stated. Ampicillin, benzylpenicillin, phenoxymethylpenicillin, and tetracycline were not affected by transport.

Conclusions-Drugs were exposed to a much higher temperature and humidity than is recom- mended by the manufacturer, especially in tropical harbours and during inland transport. Except for ergometrine and methylergometrine the transport would not affect clinical effectiveness.

\section{Introduction}

In 1987 Unicef sent over $\$ 30$ million worth of essential drugs to tropical countries. ${ }^{1}$ The stability of medicines distributed and used in hot and humid climates can pose serious problems, but stability studies and storage guidelines usually refer to temperate climates and therefore may not be relevant in extreme climatic conditions. ${ }^{2}$ Few studies have described the influence of tropical storage conditions on the quality of medicines. ${ }^{3}$ The World Health Organisation and Unicef therefore carried out a joint study on the stability of essential drugs during international transport.

\section{Materials and methods}

We used three criteria to select drugs for the study. The first criterion was an indication from WHO accelerated stability tests ${ }^{4}$ or other studies ${ }^{5-8}$ that the active substance or the drug product could be unstable in tropical climates. The other criteria were that Unicef has a high turnover of the drug in volume or in value and in medical relevance. Eleven drugs were selected. All samples were taken from normal Unicef stock, and 
products in the test and control packs were taken from the same batch.

Three sea routes were chosen that together cover 35 of the 77 countries served by Unicef and nearly $40 \%$ of the total volume of drugs dispatched in 1987. The journeys from Copenhagen to Lagos (Nigeria), to Mombasa and overland to Kampala (Uganda), and to Bangkok (Thailand) took 51, 52, and 27 days respectively $10-30 \%$ of the time was spent in the port of destination before customs clearance.

Battery operated "autolog" devices were developed that electronically measured and recorded temperature and relative humidity at three hourly intervals over 100 days. The test packs were the normal Unicef triple wall cardboard boxes containing the selected drugs and the autolog. Four test packs were included in each of the shipments and were put in different locations on board (one pack in the centre and one near the ceiling of two containers, one located in the hold and the other on deck). After arrival and clearance from customs the test packs were sent by air to the chemical laboratories of the Medical Products Agency in Uppsala, Sweden, where control packs had been kept and where the chemical analyses were done. Unfortunately, the test packs from Bangkok were returned by surface mail. The climatic recordings of that journey were used but the drugs were excuded from the analysis.

\section{Results}

The temperatures recorded within the test packs ranged from $-3.5^{\circ} \mathrm{C}$ to $33.6^{\circ} \mathrm{C}$ during the journey to Lagos, from $-2 \cdot 3^{\circ} \mathrm{C}$ to $42 \cdot 4^{\circ} \mathrm{C}$ during the journey to Kampala, and from $1.9^{\circ} \mathrm{C}$ to $37.5^{\circ} \mathrm{C}$ during the journey to Bangkok. Relative humidity ranged from $20 \%$ to $88 \%$. The temperature within the test packs was usually $3-12^{\circ} \mathrm{C}$ higher than the ambient temperature. Differences between the locations on board were negligible. The figure shows a sample recording from the trip to Mombasa and overland to Kampala.

Three of the 11 drugs (ergometrine injection, methylergometrine injection, and retinol capsules) lost $1 \cdot 5-5 \cdot 8 \%$ of their active ingredient during the journey (table). Moreover, the individual ampoules of ergometrine varied greatly, with 18 out of $80(23 \%)$ of the test samples having less than $80 \%$ of the stated content and three (4\%) less than $60 \%$. A similar but less extreme pattern was found with methylergometrine. For all drugs the decomposition products, weight variation, disintegration, and hardness were within pharmacopoeial standards and did not differ between control and test packs. ${ }^{9}$

\section{Discussion}

Both the temperature and relative humidity on the three routes showed an identical pattern: steadily rising on approaching tropical waters, then high values

Mean (95\% confidence interval) amount of active ingredient in essential drugs after international transport as percentage of stated content

\begin{tabular}{|c|c|c|c|c|}
\hline Drug & Control pack & Transported pack & Difference ${ }^{\star}$ & $\begin{array}{c}\text { Significance } \\
\text { ( } \mathrm{p} \text { value })\end{array}$ \\
\hline $\begin{array}{l}\text { Aspirin (acetylsalicylic acid) (tablet) } \\
\text { (brand a) } \\
\text { Aspirin (acetylsalicylic acid) (tablet) }\end{array}$ & $101 \cdot 0(99 \cdot 7$ to $102 \cdot 2)$ & $100 \cdot 7(99.9$ to 101.4$)$ & $-0 \cdot 3$ & NS \\
\hline & $100 \cdot 0(99 \cdot 9$ to $100 \cdot 2)$ & $100 \cdot 2(99 \cdot 7$ to $100 \cdot 8)$ & $0 \cdot 2$ & NS \\
\hline n trihydrate (capsule) & $96.4(9$ & & -0 & NS \\
\hline (injection) & $84 \cdot 1(83 \cdot 4$ to $84 \cdot 8)$ & $83.7(82.6$ to 84.9$)$ & -0.5 & NS \\
\hline njection) & $96.6(92.8$ to $100 \cdot 5)$ & $96.2(95.6$ to 96.8$)$ & -0.4 & NS \\
\hline Ergometrine & $87 \cdot 1(86 \cdot 0$ to $88 \cdot 1)$ & $82.0(80.3$ to 83.8$)$ & $-5 \cdot 8$ & $<0.001$ \\
\hline Methylergometrine (injection) & $100 \cdot 7(100 \cdot 0$ to $101 \cdot 4)$ & $99.0(98.6$ to 99.5$)$ & $-1 \cdot 7$ & $<0.001$ \\
\hline It (tablet) & $100.0(98.5$ to 101.4$)$ & $100 \cdot 1(99 \cdot 2$ to $101 \cdot 0)$ & $0 \cdot 1$ & NS \\
\hline Folic acid (tablet) $\dagger$ & $108.6(91.2$ to 125.9$)$ & $106 \cdot 6(103 \cdot 1$ to 110.0$)$ & $-1 \cdot 8$ & NS \\
\hline Phenoxymethylpenicillin (tablet) & $96 \cdot 3(94 \cdot 1$ to $98 \cdot 5)$ & $96.0(95.6$ to 96.4$)$ & $-0 \cdot 3$ & NS \\
\hline Retinol (capsule) & $120 \cdot 8(120 \cdot 2$ to $121 \cdot 4)$ & $119 \cdot 0(118 \cdot 1$ to $119 \cdot 9)$ & $-1 \cdot 5$ & $<0.001$ \\
\hline Tetracycline (tablet) & $101 \cdot 8$ & $101.5(99.5$ to 103.4$)$ & $-0 \cdot 3$ & NS \\
\hline
\end{tabular}

^As percentage of control value.

tCombined with ferrous salt in one tablet. and moderate fluctuation in tropical harbours, and high values and large fluctuations during storage and transport on land. The recorded temperature of $-3.5^{\circ} \mathrm{C}$ within the test packs, which occurred in Aarhus harbour in November was unexpected (figure).

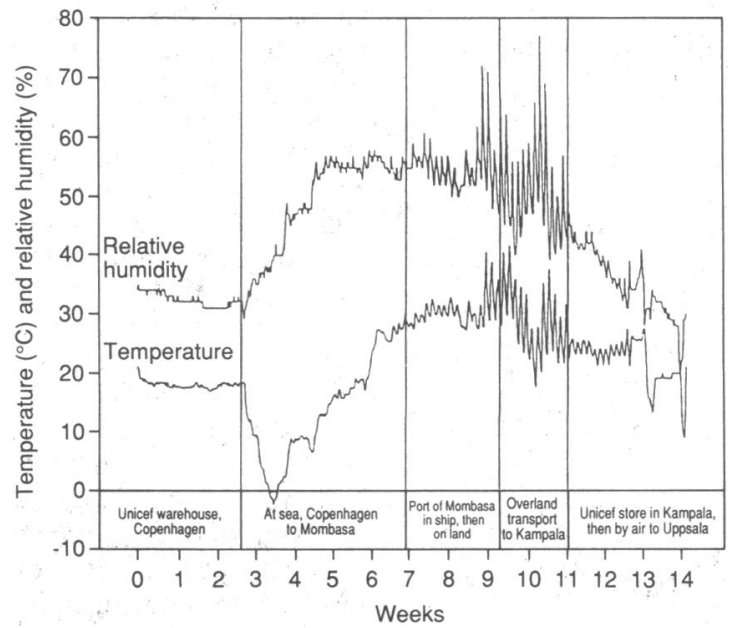

Temperature and relative humidity within one pack of drugs during transport by sea from Copenhagen to Mombasa then by land to Kampala

Only one study has been published on the climatic pattern during transport of drugs in tropical climates; this study described the temperature within a box of emergency drugs kept in a life raft on board a naval vessel during a voyage in the Indian Ocean. ${ }^{10}$ The highest temperature recorded in that box was $40 \cdot 2^{\circ} \mathrm{C}$, in Mombasa. Humidity and quality of the drugs were not studied.

The WHO defines normal drug storage conditions as dry, well ventilated premises at temperatures of 15 $25^{\circ} \mathrm{C}$ or, depending on climatic conditions, up to $30^{\circ} \mathrm{C} .^{2}$ In our study the temperature in the drug packs was at times much higher than that, with a maximum of $42.4^{\circ} \mathrm{C}$ in Mombasa. We also found that the temperature within the packs was $3-12^{\circ} \mathrm{C}$ higher than the ambient temperature and that periods of great fluctuation occurred in which expansion and contraction could cause drug packages to leak.

The temperature and relative humidity at sea were less of a problem than on land. Extreme climatic conditions occurred especially during time in the harbour and in bond in the port area, and during transport over land. Drugs were exposed to high temperature and humidity for $17(33 \%)$ days on the journey to Lagos and $26(54 \%)$ days on the journey to Kampala.

Three drugs (ergometrine, methylergometrine, and retinol) showed decreased concentrations of active ingredient after international transport. For retinol this had no medical and practical implications: the loss was only $1.5 \%$, the product contained an extra $20 \%$ of active ingredient, and the therapeutic margin is wide.

The loss of active ingredient is more important for ergometrine. In a study of 24 field samples from Bangladesh, South Yemen, and Zimbabwe only nine complied with British Pharmacopoeia requirements and seven contained less than $20 \%$ of the stated amount of active ingredient. ${ }^{6}$ Recent data from WHO on samples from Gambia, Malawi, and Zimbabwe confirm this finding. In a longitudinal study in Sudan the drug preparation lost $10 \%$ of its active ingredient during the first few months in Port Sudan and was found to contain only $53 \%$ of the stated contents after 25 months in the country.?

The large variation we found between individual ergometrine ampoules is worrying, with three out of 80 
containing less than $60 \%$ of the stated amount. This observation is much more important than the average loss of $5 \cdot 8 \%$. It should also be realised that the product had probably already lost some active ingredient before shipment and that further loss would be expected during inland transport and storage. The alarm recently expressed about ergometrine's stability in tropical climates $^{67}$ is therefore justified. There is no obvious alternative to this life saving drug and it is not known whether methylergometrine is more stable. A WHO working group concluded recently that oxytocin is the best replacement, ${ }^{11}$ but its stability in tropical climates is not known either.

None of the other drugs seemed unstable during international transport. From a medical and economic viewpoint this is particularly reassuring with regard to the common antibiotics. For most antibiotics the unprotected substance has shown signs of degradation ${ }^{4}$ as have unprotected capsules of chloramphenicol and tetracycline in simulation tests. ${ }^{5}$ For ampicillin ${ }^{12}$ and benzylpenicillin ${ }^{1314}$ high humidity or the presence of molecular water has been reported to be more damaging than high temperatures alone. These data suggest a high susceptibility of antibiotics to deterioration in hot and humid climates. However, two field studies from Sudan found no signs of instability in injections of procaine benzylpenicillin, ${ }^{7}$ benzylpenicillin, ${ }^{15}$ and ampicillin trihydrate ${ }^{15}$ and capsules of tetracycline ${ }^{7 \text { is }}$ and chloramphenicol ${ }^{15}$ and only a marginal loss in ampicillin trihydrate capsules. ${ }^{75}$ We found no stability problems with ampicillin trihydrate capsules and injection, benzylpenicillin injection, and tetracycline hydrochloride capsules. The stability of the common antibiotics in tropical climates therefore seems mainly to depend on protection against humidity, even under exposure to high temperatures.

This study was funded through grants from Unicef and Swedish International Development Authority/Swedish Agency for Research Cooperation with Developing Countries.

1 Essential drugs price list, fuly-December 1990. Copenhagen: Unicef Supply Division, 1990.

2 WHO Expert Committee on Specifications for Pharmaceutical Preparations. Thirty first report. WHO Tech Rep Ser 1990:790.

Smallenbroek H. Stability of drugs in the tropics. Groningen, Netherlands: Wetenschapswinkel voor Geneesmiddelen, 1983.

4 World Health Organisation. Accelerated stability studies of widely used pharmaceutical substances under simulated tropical conditions. Geneva: WHO, 1986. (WHO/PHARM/86.529.)

5 York P. The shelf-life of some antibiotic preparations stored under tropical conditions. Pharmazie 1977;32:101-4.

6 Walker GJA, Hogerzeil HV, Hillgren U. Potency of ergometrine in tropical countries. Lancet 1988 ;ii:393.

7 Abu-Reid IO, El-Samani SA, Hag Omer AI, Khalil NY, Mahgoub KM, Everitt G, et al. Stability of drugs in the tropics. A study in Sudan. International Pharmaceutical fournal 1990;4:6-10.

8 Longland PW, Rowbotham PC. Stability at room temperature of medicines normally recommended for cold storage. Pharmaceutical fournal 1987; January: $147-51$.

9 Hogerzeil HV, Battersby A, Srdanovic V, Hansen LV, Boye O, Lindgren B, et al. $\mathrm{WHO} /$ Unicef study on the stability of drugs during international transport. Geneva: WHO, 1991. (WHO/DAP/91.1.)

10 Becker G, Fritz HE, Mennicke W, Mobers F, Witt M. Temperaturebelastung von Arzneimitteln an Bord. Pharmazeutische Zeitung 1983;15:794-7.

11 World Health Organisation Technical Working Group. The prevention and management of postpartum haemorrhage. Geneva: WHO, 1990. (WHO/MCH/ manag.)

12 Pawelczyk E, Hermann T, Knitter B, Smilowski B. Kinetics of drug decomposition. 61. Kinetics of various ampicillin forms degradation in solid decomposition. 61. Kinetics of various ampicillin

13 Pawelczyk E, Plotkowiak Z, Knitter K, Kozakiewicz-Wegner B. Kinetics of drug decomposition. 62. Kinetics of penicillin G potassium salt (PGP) thermal degradation in solid phase. Pol $\mathcal{P}$ Pharmacol Pharm 1980;32:55-62. 14 Pikal MJ, Lukes AL, Lang JE. Thermal decomposition of amorphous $\beta$-lactam antibacterials. I Pharm Sci 1977;66:1312-6.

15 Hogerzeil HV, De Goeje M, Abu-Reid IO. Stability of essential drugs in Sudan. Lancet 1991;ii:754-5.

(Accepted II November 1991)

\section{Variability in serial CD4 counts and relation to progression of HIV-I infection to AIDS in haemophilic patients}

Louis M Aledort, Margaret W Hilgartner, Malcolm C Pike, George F Gjerset, Marion A Koerper, Eric Y C Lian, Jeanne M Lusher, James W Mosley (on behalf of the Transfusion Safety Study Group)

Abstract

Objective-To examine the CD4 count and its near term changes relative to progression to AIDS within 30 months and to subsequent CD4 counts.

Design-Longitudinal clinical and laboratory study.

Setting-Haemophilia treatment centres in six large American cities.

Patients - 555 people with congenital clotting disorders who were infected with HIV, initially without AIDS, and seen at follow up for 6-30 months in 1986-9.

Main outcome measures-Absolute $\mathrm{CD} 4$ counts and incidence of AIDS.

Results-Outset CD4 count and age were independently related to progression to AIDS $(p<0.0001$ and $p<0.005$ respectively). Patients with CD4 counts of $0.30-0.49 \times 10^{9}$ cells/1 had an age adjusted risk of AIDS within 30 months of only $9 \%$ that of patients with counts $<0.20 \times 10^{\circ} / 1$. Children under 10 years old had only $16 \%$ of the CD4 adjusted risk of AIDS of people aged $\geqslant 45$ years. Analysis of 149 patients' CD4 counts at the beginning and end of two successive six month intervals showed an average decrease of $11 \%$ in each six months regardless of the outset count $\left(\geqslant 0 \cdot 20 \times 10^{9} / 1\right)$. For individual patients the decrease in the second six month period was unaffected by the decrease in the first six month period.
Conclusions-Antiviral treatment of asymptomatic people, particularly children, with CD4 counts $\geqslant 0.3 \times 10^{\circ} / 1$ is questionable if predicated on near term progression to AIDS. Because of individual CD4 count variability and the low rate of progression to AIDS near term declines in individual CD4 counts are a poor index for identifying people who will rapidly progress to AIDS.

\section{Introduction}

The absolute CD4 count has repeatedly been found to be either the best predictor or among the best predictors of the rapidity with which HIV-I infection progresses to clinical manifestations, especially AIDS disclosed by opportunistic infections. ${ }^{1.4}$ As a consequence antiretroviral treatment is presently being administered to some people who are asymptomatic but whose CD4 counts are considered indicative of approaching AIDS.$^{5-7}$ Values that have been suggested for initiation of AIDS prophylaxis are $0 \cdot 2-0.5 \times 10^{9}$ cells/l, which if implemented could mean treatment for some 450000 to 650000 people in the United States alone. ${ }^{8}$

Although the appreciable toxic effects of zidovudine $^{9}$ are now more manageable with regimens with reduced dosage, the residual incidence of bone marrow depression, ${ }^{10}$ the cost of the drug, the need for an increased amount of medical supervision, and the
1840 North Soto Street

California 90032, USA.

BMF 1992;304:212-6 